\title{
IS THERE ANY REALITY TO THE REVERSE KAPANDJI OPERATION IN THE TREATMENT OF PROXIMAL RADIOULNAR SYNOSTOSIS? BIOMECHANICAL MEASUREMENTS
}

\author{
Henrik Rybaltovszki ${ }^{1}$, Károly Fekete ${ }^{2}$, Sándor Manó ${ }^{1}$ \\ ${ }^{1}$ Department of Orthopaedic Surgery, Medical and Health Science Center, University \\ of Debrecen \\ ${ }^{2}$ Department of Traumatology and Hand Surgery, Medical and Health Science Center, \\ University of Debrecen \\ rybaltovszki@freemail.hu
}

\begin{abstract}
The forearm, wrist and elbow joints in addition to the ligamentous system which holds the two bones together make up a combined joint with complex movement. Within this joint framework, injury at any point can result in profound biomechanical changes leading to functional alterations. Such an alteration is the bony bridge between the radius and ulna which is blocking the rotational movements. Surgical treatment can be instead of the resection of the bridge-callus creating a defect on the radius distally to the synostosis. This leads to a "reverse" Sauvé-Kapandji situation and to the disintegration of the bony frame of the forearm. The authors examined the stabilizing effect of the ligamentous system which holds the framework together, with emphasis on the role of the interosseous membrane.

Measurements of rotational motion in various stages in the forearm were performed on fresh cadaver forearm preparations in both intact cases and also following the excision of a proximal segment of the radius. The movements were measured and registered using an Instron 8874 biomechanical material testing machine. In addition to registration, both fixed and mobile digital recording was done.

The stabilizing role of the interosseous membrane in supination was only effective when the radius was of normal length. The excision of the radial segment seriously damaged both the rotational motion and the stability of the wrist.
\end{abstract}

Keywords: bridge callus, forearm fracture, Kapandji procedure, fractures of radius and ulna, interosseal membrane

\section{Introduction}

Synostosis which develops between the radius and ulna following forearm fracturewhether treated conservatively or surgicallycauses significant loss of function. The bridge callus which develops and goes untreated will permanently block pro- and supination which are determining factors in the usage of the hand. Vince and Miller worked up 2381 cases in the literature and found an incidence of $2 \% 1,5$. Other literary data place the incidence below $5.5 \%$ following conservative therapy and a $9.5 \%$ incidence in cases that were treated surgically. Treatment is only surgical; resection of the synostosis and interpositioning of either connective or synthetic tissue $^{6,7}$. 


\section{Clinical practice}

Many factors promote the development of the bridge callus:

1. Fracture type

- Fractures of the proximal one-third of the forearm

- Fragmented Monteggia injuries

- Fractures of the radius and ulna at the same level

- Floating elbow

- Comminuted fractures of the radial head

2. Serious local connective tissue trauma

- Open fracture

- Injury of the interosseous membrane

- rupture of the distal biceps tendon

3. Polytrauma, craniocerebral injury, longterm endotracheal intubation

4. Factors related to treatment

- Surgery performed one week after injury

- Unstable osteosynthesis

- Plaster casting of the limb following osteosynthesis

- Traumatizing surgical technique

- Long screws which reach the interosseous space

- Incorrect placement of the plate

- Primary spongioplasty which touches the interosseous membrane

- Dislocated broken fragment

- Surgical approach (Boyd 50\%).

\section{What possibilities exist for the treatment of} synostosis?

The aim of surgical treatment is anatomical reduction, stable osteosynthesis and the prevention of the development of bridge callus.

If the bridge callus develops despite this, resection of the callus is the solution.

- Timing: Vince and Miller advise the operation 1-2 years after injury, Jupiter and Ring usually perform reconstruction within one year ${ }^{6,9}$.
- Atraumatic surgical technique: in the interests of decreasing the possibility of relapse, emphasis is put on arresting bleeding and treating the bleeding bone surfaces using bone wax.

- Interpositional arthroplasty: fat, muscle tissue interpositioning, or in some cases the use of the fascia lata or silicone membrane.

Our results of the previously discussed methods were quite modest. In the literature that we found (Vince, Miller, Failla) ${ }^{2,9}$, the motion amplitude achieved during surgery decreased to close to half in the late postoperative stage. Although Jupiter report somewhat better results $^{6}$, we had to think of some other form of these surgical procedures.

\section{The Sauvé-Kapandji operation}

In 1936 Sauvé and Kapandji presented their intervention ${ }^{8}$. The main idea of which was the formation of arthrodesis between the distal radius and ulna as well as the formation of a pseudoarthrosis on the shaft of the ulna proximal to the fusion. This ensured the improvement of the decreased pronation and supination caused by the distal radio-ulnar arthritis. The preservation of the ulnar head prevents the late complications caused by the resection, and allows an almost normal transmission of strength as well as providing better support to the proximal bones of the hand. The tendon of the extensor carpi ulnaris is guided appropriately and the outward appearance of the wrist is preserved.

\section{The reversed Sauvé-Kapandji operation}

One of the authors of this article brought up the possibility that the blocked forearm movement could be improved not by the resection of the bridge callus but with the placement of 
the rotation more distally ${ }^{3,4}$. With regard to technique this means a resection of a segment of the radius which would be performed distally to the synostosis and the radial tuberosity. Is this "reverse" Sauvé-Kapandji operation sufficient for the restoration of rotation, or can the interosseous membrane ensure the stability of the radius on its own?

\section{Materials and Methods}

The function of the membrane was exemined using an Instron 8874 biomechanical testing machine (Figure 1,2) and measurements were performed using preparations of the radius and ulna which included the elbow and approximately $8 \mathrm{~cm}$ of distal humerus and having only ligamentous and joint capsule connections.

The preparations were secured as follows: the distal humerus was fixed to a table. DC plate was bent to 90 degrees. The elbow was

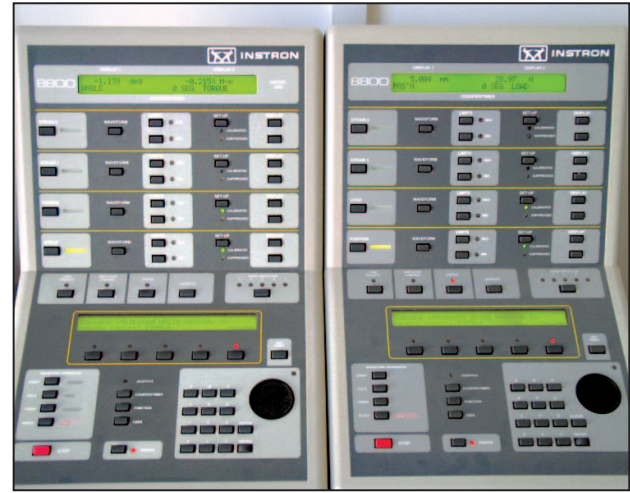

Figure 1. The consols of the Instron 8874 biomechanical material testing machine

flexed in 90 degrees then the plate was fixed by screws to the proximal ulna and to the table. In this way, the forearm was fixed proximally with the elbow in 90 degrees of flexion, thus allowing for pro- and supination and it was perpendicular to the table. Another plate was screwed onto the distal radius which allowed the grip of the material testing machine to grasp it (Figure 2, 3, 4).

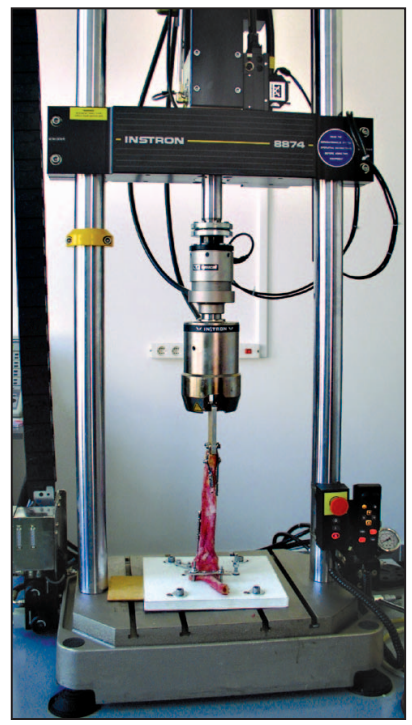

Figure 2. Securing the preparations into the material testing machine

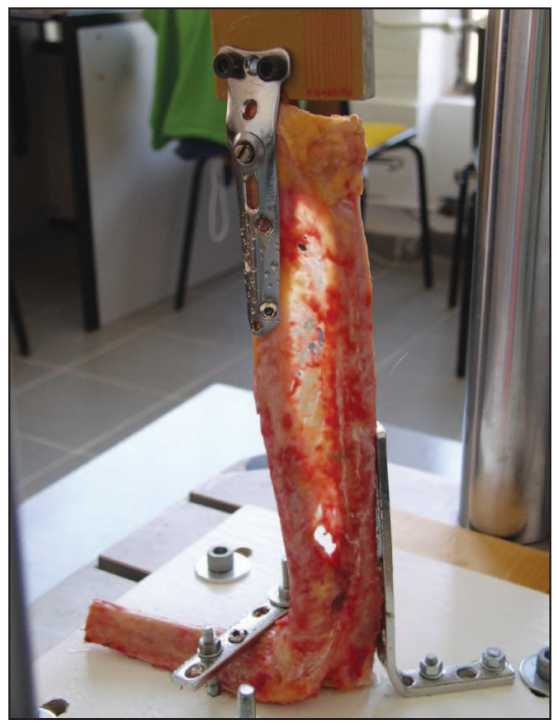

Figure 3. Maximal supination

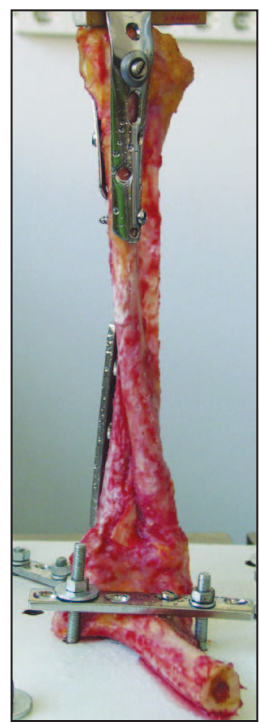

Figure 4. Maximal pronation 


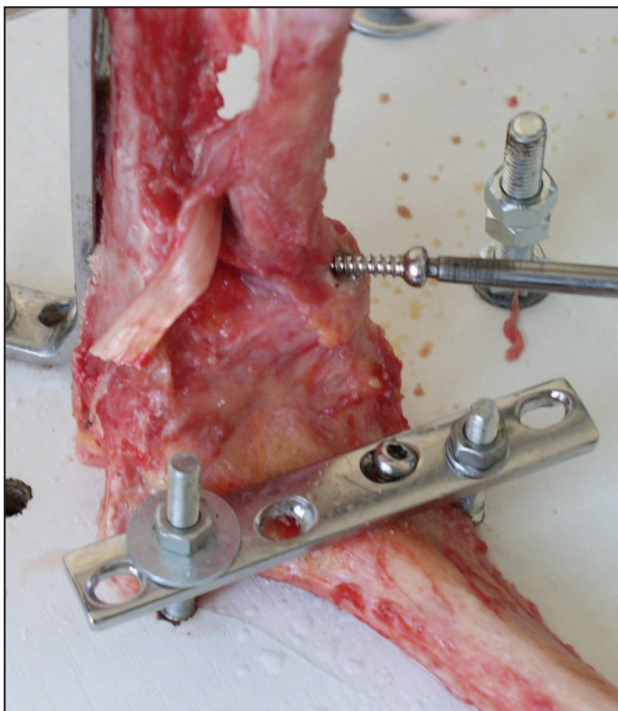

Figure 5. Preparing the artificial synostosis

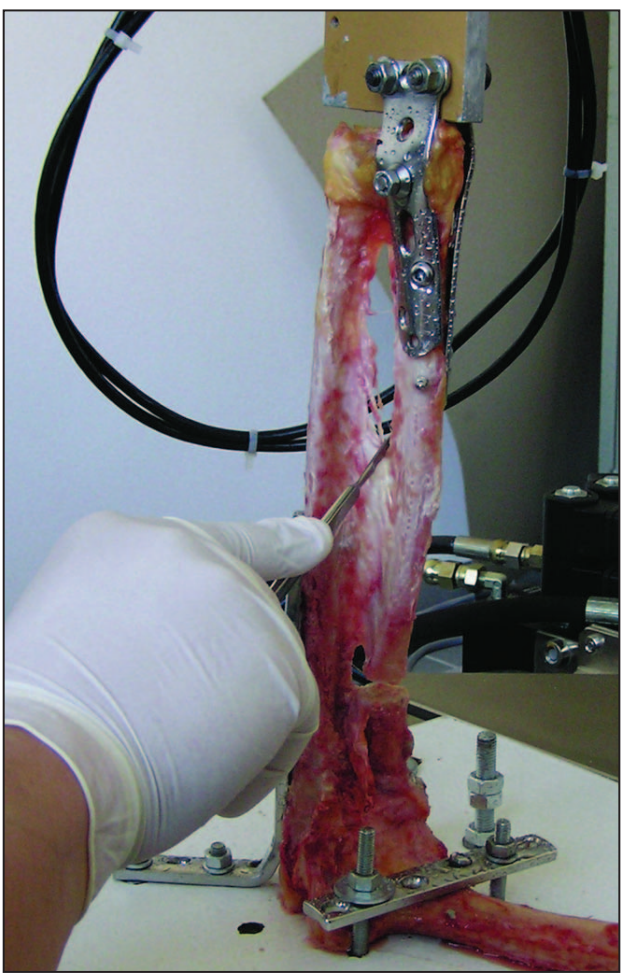

Figure 7. Cleaving the interosseal membrane

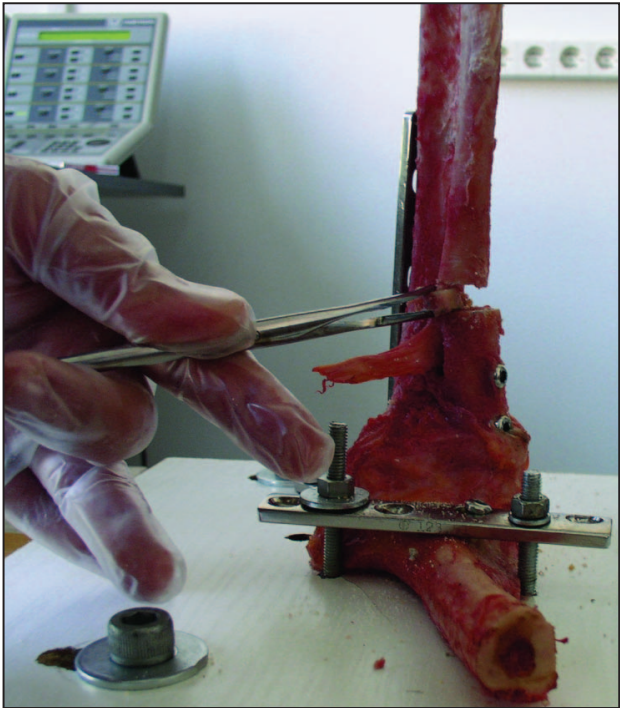

Figure 6. Performing the osteotomy

During our biomechanical experiments, the stability of the system was examined, and the range of motion and capacity of resistance to applied force following the preparation of an artificial synostosis were measured.

The preparations were fixed into the material testing machine in 90 degrees of flexion and were loaded in their axis with $100 \mathrm{~N}$ and $200 \mathrm{~N}$ of tension and then compression force and conclusions were drawn regarding the stability of the system following the measurement of displacement. The displacement was measured in millimeters. The measurements were performed in mid position, at 30 and 60 degrees of pronation as well as in 30-60-90 degrees of supination.

The measurements were primarily done on intact forearm preparations, and these were assessed as reference values.

Following this, the radial head was fixed to the ulna in neutral position using 2 cortical screws (Figure 5), thereby preparing the artificial syn- 
ostosis. By sawing a $4 \mathrm{~mm}$ disc $4 \mathrm{~mm}$ distally to the radial tuberosity it was possible to bring about the reverse Sauvé-Kapandji situation, then the measurements were retaken (Figure 6).

Finally, the measurements were also performed following partial cleavage as well as total cutting through the interosseous membrane (Figure 7).

\section{Results}

The measurements were primarily done on intact forearm preparations (Table 1).

\begin{tabular}{|c|c|c|c|}
\hline $\begin{array}{l}\text { Rotation (degree) } \\
\text { negative - pronation } \\
\text { positive - supination }\end{array}$ & $\begin{array}{c}\text { Force }(\mathbf{N}) \\
\text { negative }- \text { compression } \\
\text { positive }- \text { tension }\end{array}$ & $\begin{array}{l}\text { Position (mm) } \\
\text { (relative to the zero point } \\
\text { of the machine) }\end{array}$ & $\begin{array}{l}\text { Displacement }(\mathrm{mm}) \\
\text { (relative to the unloaded } \\
\text { position) } \\
\text { negative }- \text { down } \\
\text { positive - up }\end{array}$ \\
\hline \multirow{5}{*}{-60} & -200 & 2.949 & -0.307 \\
\hline & -100 & 3.061 & -0.195 \\
\hline & 0 & 3.256 & 0 \\
\hline & 100 & 4.475 & 1.219 \\
\hline & 200 & 6.34 & 3.084 \\
\hline \multirow{5}{*}{-30} & -200 & 3.474 & -0.68 \\
\hline & -100 & 3.648 & -0.506 \\
\hline & 0 & 4.154 & 0 \\
\hline & 100 & 6.36 & 2.206 \\
\hline & 200 & 7.727 & 3.573 \\
\hline \multirow{5}{*}{0} & -200 & 4.212 & -0.705 \\
\hline & -100 & 4.382 & -0.535 \\
\hline & 0 & 4.917 & 0 \\
\hline & 100 & 7.1 & 2.183 \\
\hline & 200 & 8.116 & 3.199 \\
\hline \multirow{5}{*}{30} & -200 & 3.981 & -0.422 \\
\hline & -100 & 4.159 & -0.244 \\
\hline & 0 & 4.403 & 0 \\
\hline & 100 & 5.702 & 1.299 \\
\hline & 200 & 7.158 & 2.755 \\
\hline \multirow{5}{*}{60} & -200 & 3.303 & -0.45 \\
\hline & -100 & 3.571 & -0.182 \\
\hline & 0 & 3.753 & 0 \\
\hline & 100 & 4.444 & 0.691 \\
\hline & 200 & 5.757 & 2.004 \\
\hline \multirow{5}{*}{90} & -200 & 2.409 & -0.472 \\
\hline & -100 & 2.707 & -0.174 \\
\hline & 0 & 2.881 & 0 \\
\hline & 100 & 3.641 & 0.76 \\
\hline & 200 & 4.338 & 1.457 \\
\hline
\end{tabular}

Table 1. The results of the measurements on intact forearm - reference values 
Then we performed the reverse SauvéKapandji situation, then the measurements were retaken (Table 2).

Then in this "reverse" Sauvé-Kapandji situation the interosseal membrane was partially cleaved and after that it was totally cutted through. The results of the forearm with patially cleaved interosseal membrane can be seen on Table 3, the results of the total cutting through on the Table 4.
Position (mm) negative - pronation positive - supination
Force (N) negative - compression positive - tension (relative to the zero point of the machine)
Displacement (mm) (relative to the unloaded position) negative - down positive - up
$-60$

\begin{tabular}{|c|c|c|}
\hline-200 & & positive - up \\
\hline-100 & 0.696 & -3.715 \\
\hline 0 & 1.155 & -3.256 \\
\hline 100 & 4.411 & 0 \\
\hline
\end{tabular}

$-30$

0

30

60

90

\begin{tabular}{|c|c|c|}
\hline 0 & 4.411 & 0 \\
\hline 100 & 9.463 & 5.052 \\
\hline 200 & 15.74 & 11.329 \\
\hline-200 & 0.289 & -2.261 \\
\hline-100 & 0.955 & -1.595 \\
\hline 0 & 2.55 & 0 \\
\hline 100 & 9.15 & 6.6 \\
\hline 200 & 15.64 & 13.09 \\
\hline-200 & 0.855 & -2.468 \\
\hline-100 & 1.924 & -1.399 \\
\hline 0 & 3.323 & 0 \\
\hline 100 & 8.555 & 5.232 \\
\hline 200 & 15.11 & 11.787 \\
\hline-200 & 1.024 & -2.072 \\
\hline-100 & 1.924 & -1.172 \\
\hline 0 & 3.096 & 0 \\
\hline 100 & 7.239 & 4.143 \\
\hline 200 & 14.27 & 11.174 \\
\hline-200 & 1.069 & -1.81 \\
\hline-100 & 1.859 & -1.02 \\
\hline 0 & 2.879 & 0 \\
\hline 100 & 6.278 & 3.399 \\
\hline 200 & 14.95 & 12.071 \\
\hline-200 & 0.904 & -2.048 \\
\hline-100 & 1.851 & -1.101 \\
\hline 0 & 2.952 & 0 \\
\hline 100 & 6.802 & 3.85 \\
\hline 200 & 16.14 & 13.188 \\
\hline
\end{tabular}

Table 2. The results of the measurements on "reverse" Sauvé-Kapandji situation 


\begin{tabular}{|c|c|c|c|}
\hline $\begin{array}{l}\text { Rotation (degree) } \\
\text { negative - pronation } \\
\text { positive - supination }\end{array}$ & $\begin{array}{c}\text { Force }(\mathbf{N}) \\
\text { negative }- \text { compression } \\
\text { positive }- \text { tension }\end{array}$ & $\begin{array}{l}\text { Position }(\mathrm{mm}) \\
\text { (relative to the zero point } \\
\text { of the machine) }\end{array}$ & $\begin{array}{c}\text { Displacement }(\mathrm{mm}) \\
\text { (relative to the unloaded } \\
\text { position) } \\
\text { negative }- \text { down } \\
\text { positive - up }\end{array}$ \\
\hline \multirow{5}{*}{-60} & -200 & 0.612 & -3.09 \\
\hline & -100 & 1.233 & -2.469 \\
\hline & 0 & 3.702 & 0 \\
\hline & 100 & 14.93 & 11.228 \\
\hline & 200 & 16.72 & 13.018 \\
\hline \multirow{5}{*}{0} & -200 & 0.77 & -2.33 \\
\hline & -100 & 1.652 & -1.448 \\
\hline & 0 & 3.1 & 0 \\
\hline & 100 & 15.09 & 11.99 \\
\hline & 200 & 17.36 & 14.26 \\
\hline \multirow{5}{*}{90} & -200 & 1.041 & -2.412 \\
\hline & -100 & 1.969 & -1.484 \\
\hline & 0 & 3.453 & 0 \\
\hline & 100 & 15.26 & 11.807 \\
\hline & 200 & 17.82 & 14.367 \\
\hline
\end{tabular}

Table 3. The results of the measurements on "reverse" Sauvé-Kapandji situation the interosseal membrane partially cleaved

\begin{tabular}{|c|c|c|c|}
\hline $\begin{array}{l}\text { Rotation (degree) } \\
\text { negative - pronation } \\
\text { positive - supination }\end{array}$ & $\begin{array}{c}\text { Force }(\mathbf{N}) \\
\text { negative }- \text { compression } \\
\text { positive }- \text { tension }\end{array}$ & $\begin{array}{l}\text { Position }(\mathrm{mm}) \\
\text { (relative to the zero point } \\
\text { of the machine) }\end{array}$ & $\begin{array}{l}\text { Displacement }(\mathrm{mm}) \\
\text { (relative to the unloaded } \\
\text { position) } \\
\text { negative }- \text { down } \\
\text { positive }- \text { up }\end{array}$ \\
\hline \multirow{5}{*}{-60} & -200 & -4.11 & -2.123 \\
\hline & -100 & -3.92 & -1.933 \\
\hline & 0 & -1.987 & 0 \\
\hline & 100 & 19.23 & 21.217 \\
\hline & 200 & & \\
\hline \multirow{5}{*}{0} & -200 & -2.66 & -3.762 \\
\hline & -100 & -1.305 & -2.407 \\
\hline & 0 & 1.102 & 0 \\
\hline & 100 & 16.15 & 15.048 \\
\hline & 200 & & \\
\hline \multirow{5}{*}{90} & -200 & -8.658 & -9.76 \\
\hline & -100 & -1.305 & -2.407 \\
\hline & 0 & 1.102 & 0 \\
\hline & 100 & 16.15 & 15.048 \\
\hline & 200 & & \\
\hline
\end{tabular}

Table 4. The results of the measurements on "reverse" Sauvé-Kapandji situation - the interosseal membrane totally cutted through. Red letters: the resected bone ends touched. At a force of $200 \mathrm{~N}$ of tension, the distal radioulnar joint was ripped apart. Max. force was 110-120 N app. 


\section{Conclusion}

During experimentation it was observed that the interosseous membrane slackens during pronation, thus the intact proximal and distal radioulnar joints, the two bones of the forearm acting as a framework as well as the crossing over of the radius and ulna ensure the stability of the forearm.

During supination, the interosseous membrane tightens thus increasing stability, but an intact bony structure is also necessary.

Following resection, it was observed that the proximal end of the radius underwent a pendulum motion during pronation. Significant displacement was observed both in pronation and supination when force was applied (16.6 times the reference value!), which obviously signified a significant decrease in stability. With an intact interosseous membrane, the loss of stability is more significant during pronation.

After cleaving the interosseous membrane (Table 3), displacement was increased during tension, but the striking deviations were experienced during supination. The displacement was 5-10 times the reference value, but this difference was even more significant than the situation following the removal of a segment.

When the interosseous membrane was completely cut, the system completely disintegrated; when force was applied the resected bone ends touched, and at a force of $200 \mathrm{~N}$ of tension, the distal radioulnar joint was ripped apart.

In light of the above, it is our opinion that the reconstruction of a stable bony framework and the pro- and supination motion axes using the reversal of the Kapandji operation alone is not sufficient for the improvement of movement in a blocked forearm.

The solution could be a prosthesis which allows rotational motion and ensures stability, and this will be the aim of future experimentation.

resszusa, 2002.04.19-20; Debrecen, Hungary, Congress presentation

5. Großner D, Schöttle H, Jungbluth K. Brückencallus nach Plattenosteosynthese bei Unterarmfrakturen Hefte zur Unfallheilkunde 1989;201: $272-3$.

6. Jupiter JB, Ring D. Operative treatment of post-traumatic proximal radioulnar synostosis. J Bone Joint Surg Am 1998;80:248-57.

7. Ring D, Jupiter JB. Operation posttraumatischer proximaler radioulnarer Synostosen. Operative Orthopädie und Traumatologie 2000;4;261-71.

4. Fekete K, Baktai J. Radioulnaris synosthosis protézis. Magyar Kézsebészeti Társaság IX. Kong- 
8. Sauvé L, Kapandji M. Nouvelle technique de traitement chirurgical des luxations récidivantes isolées de l'extrémité inférieure du cubitus. J Chir 1936;47;589-94.
9. Vince $K G$, Miller JE. Cross-union complicating fracture of the forearm. J Bone Joint Surg Am 1987;69:640-53.

\section{Dr. Henrik Rybaltovszki}

Department of Orthopaedic Surgery, Medical and Health Science Center, University of Debrecen H-4032 Debrecen, Nagyerdei krt. 98.

Tel.: (+36) 52 255-604

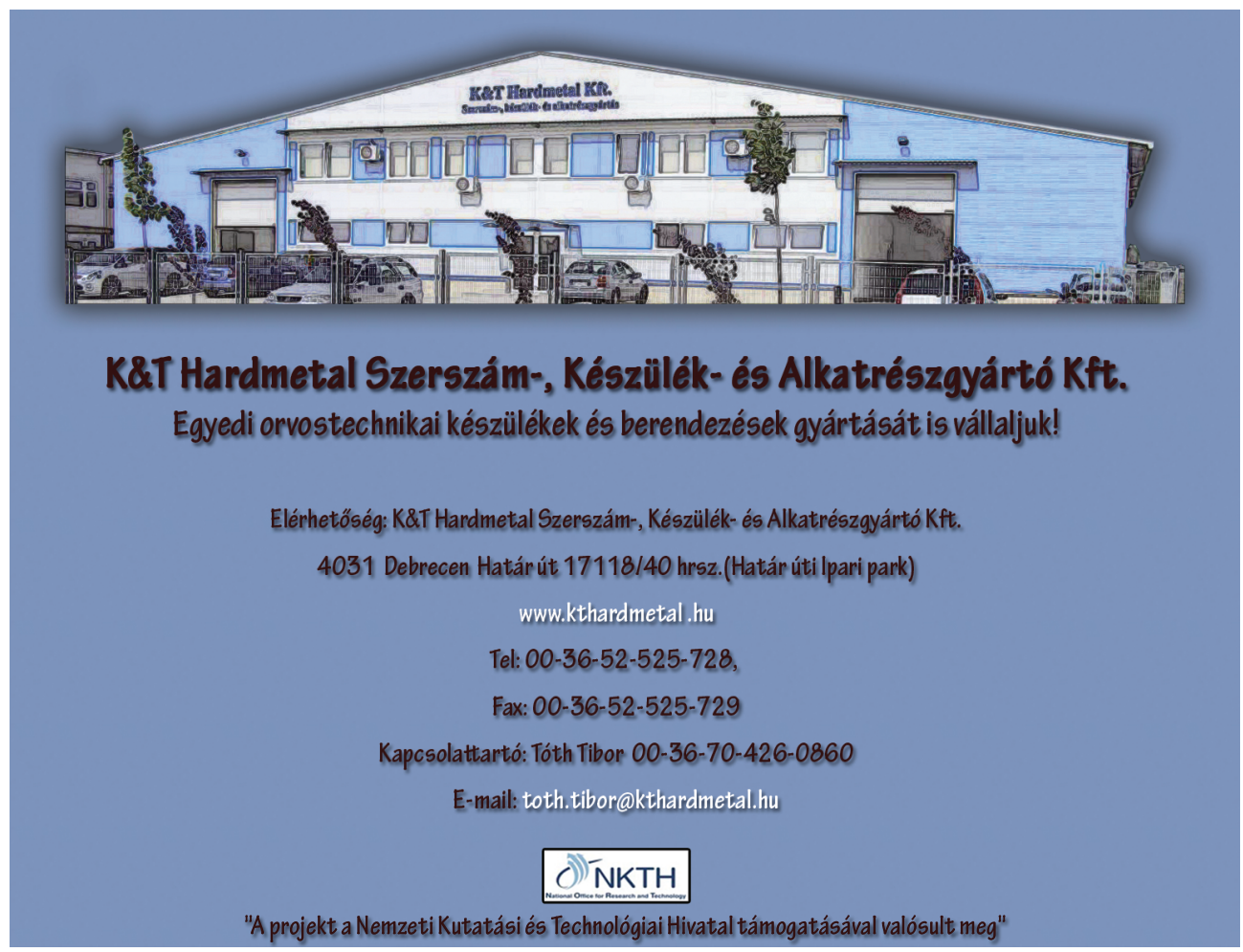

